\title{
Integrated Approach for a Knowledge-Based Process Layout for Simultaneous 5-Axis Milling of Advanced Materials
}

\author{
F. Klocke, T. Bergs, M. Busch, L. Rohde, M. Witty, and G. F. Cabral \\ High-Performance Cutting, Fraunhofer Institute for Production Technology (IPT), Steinbachstraße 17, 52074 Aachen, Germany \\ Correspondence should be addressed to M. Busch, marc.busch@ipt.fraunhofer.de
}

Received 18 May 2011; Accepted 31 May 2011

Academic Editor: Alexander Tsouknidas

Copyright () 2011 F. Klocke et al. This is an open access article distributed under the Creative Commons Attribution License, which permits unrestricted use, distribution, and reproduction in any medium, provided the original work is properly cited.

\begin{abstract}
Advanced materials, like nickel-based alloys, gain importance in turbomachinery manufacturing, where creating complex surfaces constitute a major challenge. However, milling strategies that provide high material removal rates at acceptable tooling costs demand optimized tool geometry and process parameter selection. In this paper, a description of circular milling is given, focusing on resulting engagement conditions. Regarding this, a test bench was designed to investigate the chip formation process in an analogy milling process. Furthermore, the methodology for the approach in the analogy process was developed. Results of a first test run in Inconel 718 verify the presented approach.
\end{abstract}

\section{Introduction and Motivation}

1.1. Applications. Increasing demands in the turbomachinery sector lead to further use of advanced materials with distinguished physical properties, resulting in high thermal and mechanical loads during machining [1-3]. A common task is the manufacture of complex geometrical features, that can be abstracted to notches or slots described by two or three boundaries, as they occur, for example, in the geometries of Blisks (blade integrated discs), single blades, and landing gears; see Figure 1.

Due to the complexity of such geometries and the limited machinability of the applied materials, milling in five axis simultaneously becomes essential. For instance, nickel-based alloys possess a low thermal conductivity, high rigidity, low elastic modulus, and high chemical reactivity at elevated temperatures. Furthermore, they are characterized by a lamellar chip formation process leading to dynamic fatigue stress at the tool and hence to an increased tool wear [4-8]. All these characteristics restrain the feasible range of cutting parameters. Furthermore, the high aspect ratios of the complex geometries require the usage of tools with long shafts and small diameters, which restrains the process velocities even more. For milling such components, several different strategies have been used in the past $[9,10]$. However, to provide an economic process, the realization of high material removal rates at acceptable tooling costs is necessary. Hence, the manufacturing process has to be designed in a way that geometrical, qualitative, and economical requirements can be fulfilled efficiently. Herefrom, the demand for an integrated approach for a knowledge-based process layout originates which links a comprehensive understanding of the chip formation process to the resulting loads at the tool.

1.2. Roughing Strategies. The major characteristics while machining advanced materials like nickel-based alloys are high temperatures within the cutting zone, high mechanical loads at the tool, and high dynamic loads resulting from the lamellar chip formation process $[4-6,11]$. However, machining such alloys is possible even under efficient conditions but it requires innovative milling strategies based on an optimized knowledge-based process layout. For instance, the roughing process has to show high material removal rates. To realize this, usually a large portion of the tool is in contact with the material. An important variable for characterizing this contact is the (radial) tool engagement described by the engagement angle $\Phi_{c}$. Large tool engagement angles cause long contact times between the tool and the workpiece. Combined with the low thermal conductivity of the given material, this leads to high temperatures and short tool life. A milling process with large engagement angles is, for 


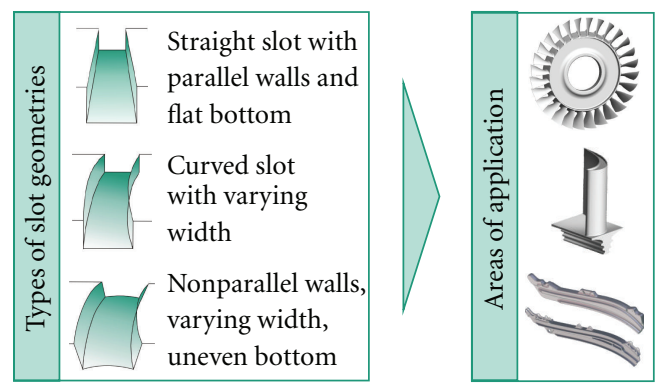

Figure 1: Areas of application.

example, the conventional slot milling. Here, engagement angles can reach up to $180^{\circ}$; see Figure 2 (a). Besides the high engagement angle, this milling technique leaves only limited potential for process optimizations. So, the target for a high-performing milling strategy is a high material removal rate at moderate engagement angles. Processes with small(er) contact angles are, for example, flank milling operations. The engagement angle is directly affected by the radial cutting width $a_{e}$. Hence, flank milling assures more freedom to vary the technological cutting parameters in a wide range. The velocity may be increased up to four times compared to conventional slot milling, and cutting depths of twice the tool diameter become possible [11]. However, a pre-machined/opened slot is required for such process conditions. Circular milling (also: trochoidal milling) is a machining strategy that takes advantage of the beneficial aspects of flank milling even for closed slots. This strategy also provides the milling of complex geometries as presented in Figure 1 and has shown to be favourable for milling advanced materials $[10,12,13]$. The most simple case of trochoidal milling is described in Figure 2(b), a straight slot with a constant width and parallel walls. Machining such a slot can be conducted by defining a circle and shifting this circle by a concrete cutting width. Finally, a transition condition between the circles has to be defined to ensure a harmonic tool path. However, the portion of unproductive tool motion is relatively high which indicates a high optimization potential for the process layout.

\subsection{Objectives and Challenges for the Process Layout. Altintas} and Lazoglu already analyzed, described, and modelled trochoidal processes $[10,14]$. Klocke et al. presented a modelbased optimization of trochoidal roughing and focused on the beneficial aspect of applying large cutting depths [11]. However, a further crucial aspect in order to assure a knowledge-driven process layout is a detailed understanding of the chip formation process while machining, which has to be linked to the resulting loads at the tool. Solely, the feed rate $f_{z}$ and the cutting speed $v_{c}$ are insufficient for designing complex milling tasks, as presented in $[15,16]$. Consequently, based on a description of circular milling, this paper is focussing on the resulting engagement conditions and links them to the occurring loads at the tool. Regarding this, an innovative test bench will be presented which allows a detailed investigation of the chip formation process in an analogy milling process. Furthermore, the methodology for the approach in the analogy process will be presented.

\section{Theoretical Process Analysis}

2.1. Circular Milling. In circular milling operations, the diameter of the tool is smaller than the slot width and the tool follows a circular path from one slot flank to the other. Thereby, the geometry of the tool path is constrained to only two defined positions per path segment; see Figure 2(b). These points are preset by the desired slot geometry, whereas all other points of the tool path can be chosen freely by the process designer according to favourable cutting conditions. Varying the diameter of the circles allows to vary the slot width and by tilting the tool axis, nonparallel slot walls can be created; see Figure 1. In principle, the process consists of two major sections-a material removal process and a retral movement without any contact between tool and workpiece; see Figure 3(a). The local thickness of the chip to be removed (highlighted in Figure 3(b)) is changing essential during the circular movement of the tool. This results in heavy alternating thermal and mechanical loads at the tool [10].

2.2. Macroscopic Contact Analysis. The contact conditions on macroscopic scale focus on the tool's outer contour penetration of the workpiece described by the engagement angle. Thereby, workpiece and tool can be modeled with different approaches of computer-based geometric simulations. The system used here is based on the so-called dexel model, where the workpiece is represented as a set of closely aligned nails or dexels; the tool is represented by a cylinder $[17,18]$. The engagement angle analysis of a circular tool path shows a distribution as displayed in Figure 4 for various cutting widths.

As the maximum of removed material correlates with the maximum tool engagement, demand for further path optimization to keep the engagement angle constant on high levels becomes obvious; see Figure 5(a). Referring to this, another analysis exhibits that variations of the tool path geometry are leading to different maximum effective tool engagements; see Figure 5(b). This can remarkably reduce the processing time of trochoidal milling [11].

This shows on the one hand that the macroscopic contact conditions for linear flank milling are not valid for circular tool paths and on the other hand the importance of optimizing the engagement conditions.

2.3. Microscopic Contact Analysis. The contact conditions on microscopic scale are obtained by using the actual tool geometry and considering the translational and rotatory tool movement. The contact condition describes the contact between the chip face and the uncut chip. It can be explained by mainly two parameters, the local thickness of the chip to be removed $h_{\mathrm{sp}}$ and the related cross-section of the chip $A_{\text {sp. }}$. The cross-section represents the amount of material in front of the cutting edge; see highlighted area in Figure 3(b). 


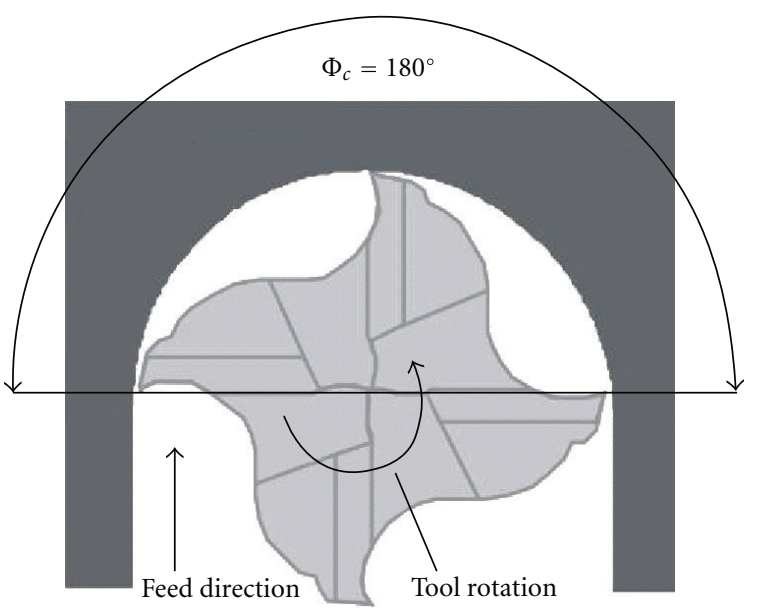

(a)

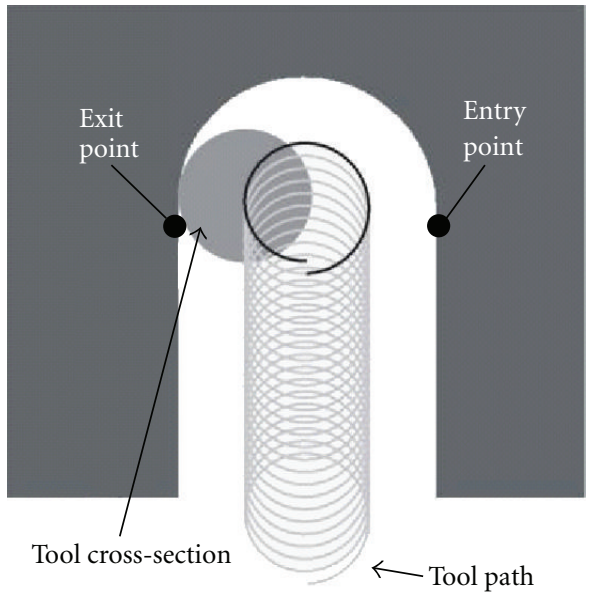

(b)

Figure 2: (a) Conventional slot milling; (b) Circular milling.

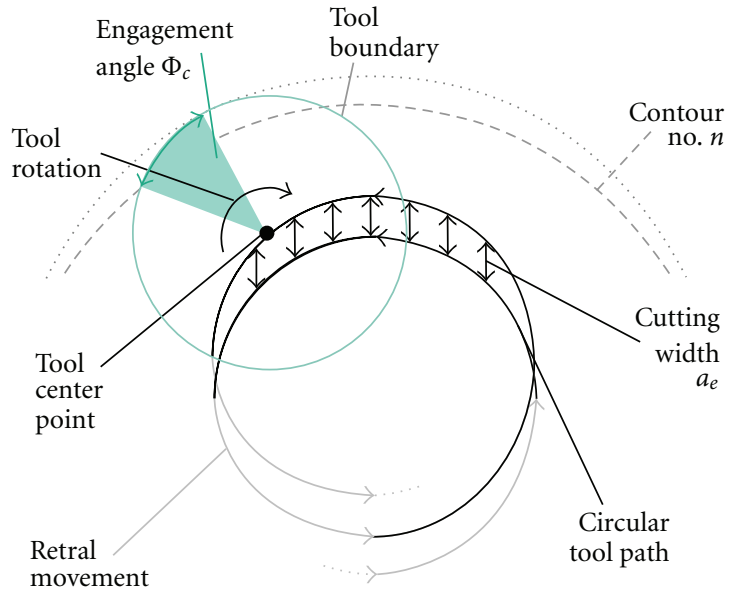

(a)

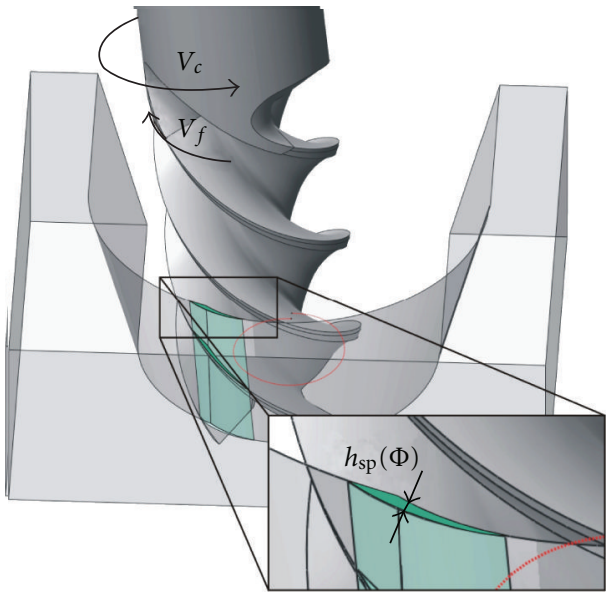

(b)

FIgURe 3: Macroscopic (a) and microscopic (b) contact conditions of circular milling.

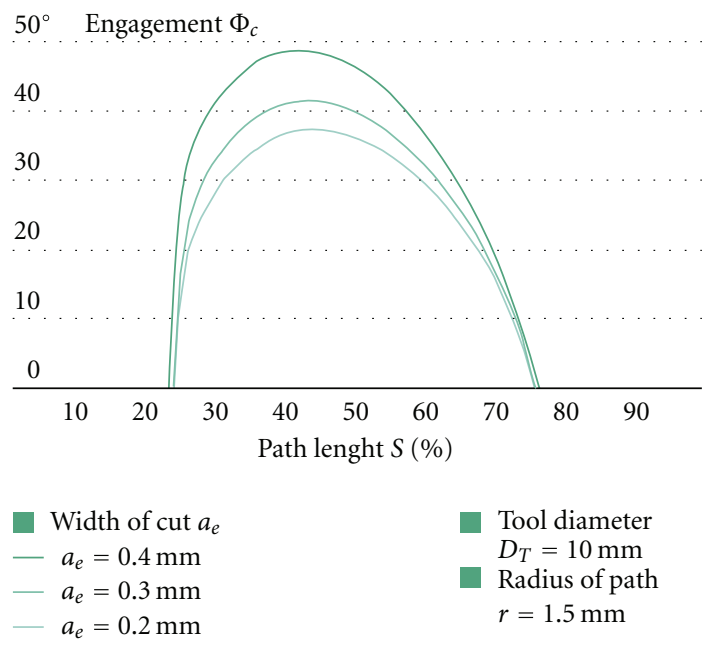

Figure 4: Influence of the cutting width $a_{e}$.
Exemplary, Figure 6(a) shows the influence of the tool path radius on the uncut chip thickness. With regards to the maximum values of $h_{\mathrm{sp}}$, the influence is negligible. In contrast to the macroscopic contact conditions, it is thus legitimate to apply the known formulas for calculation of the microscopic contact conditions for linear tool paths to circular and trochoidal tool path as well. The influence of the feed per tooth $f_{z}$ and the cutting width $a_{e}$ on the uncut chip thickness is significantly higher, as it is exemplary shown in Figure 6(b). Similar tendencies can be found for the dependencies of the chip cross-section $[11,19]$. This shows the high potential of optimizing the technological cutting conditions along the whole tool path. The optimization is mainly triggered by two aspects, the identification of a compromise between the engagement angle $\Phi_{c}$, the cutting velocity $v_{c}$, and the maximum uncut chip thickness $h_{\mathrm{sp} \text {, max }}$ and the investigation of an optimized tool geometry. Therefore, a novel test bench is applied. 
50 Engagement $\Phi_{c}\left(^{\circ}\right)$

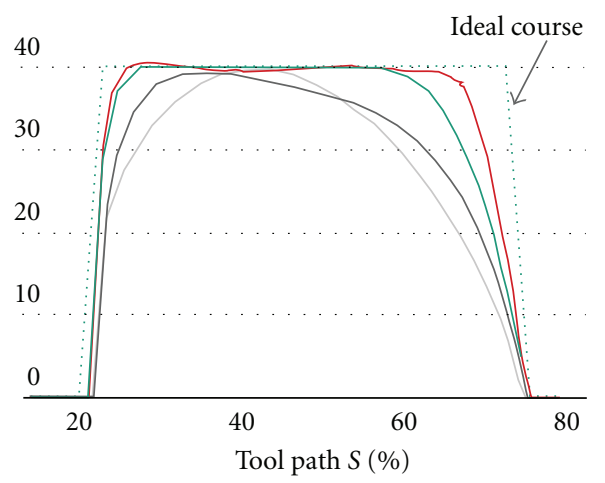

(a)
0.6 Effective engagement $a_{e, \text { eff }}(\mathrm{mm})$

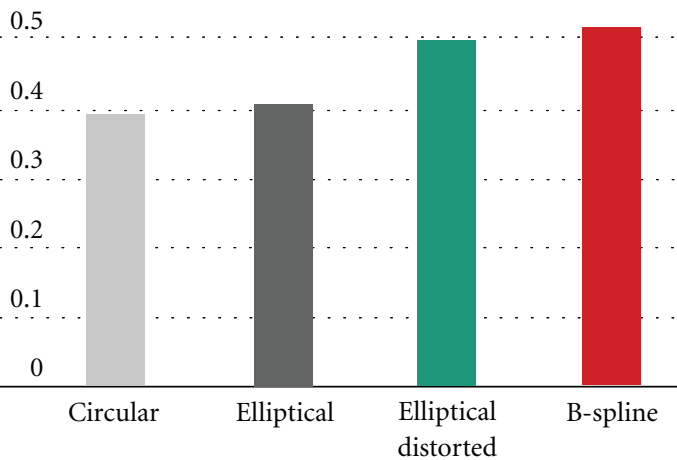

(b)

FIGURE 5: Optimized tool path geometries (a) and their influence on the effective tool engagements (b).

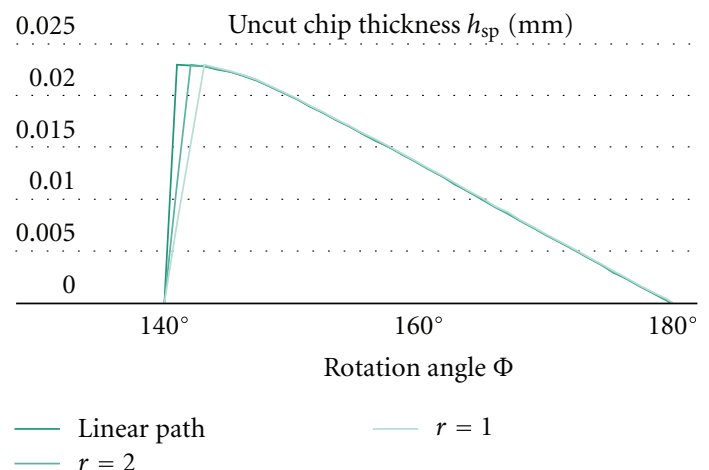

(a)

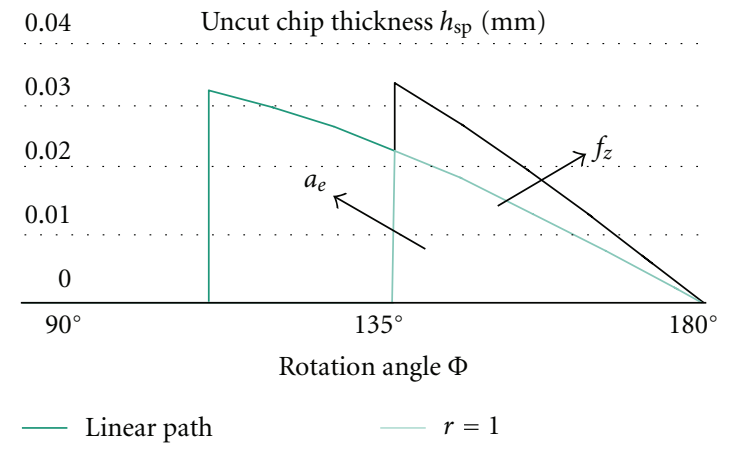

(b)

FIGURE 6: Sensitivity of the uncut chip thickness.
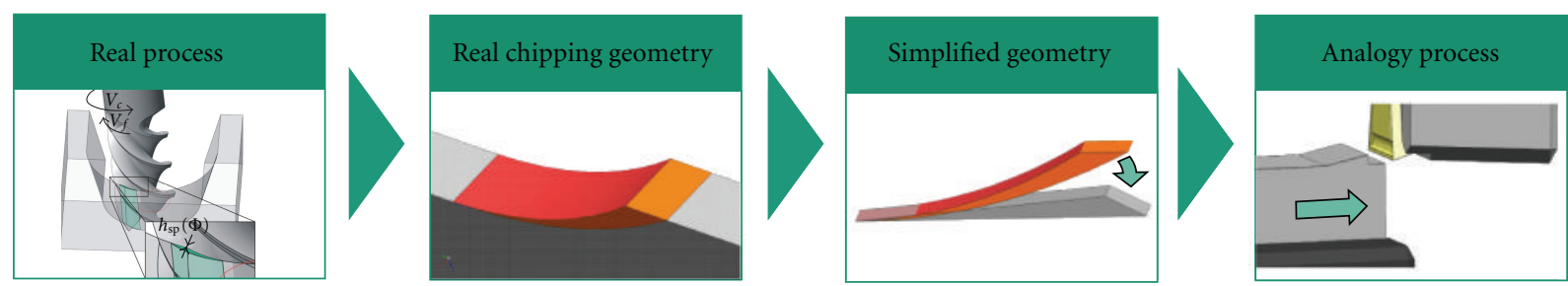

FiguRE 7: Transformation from the real to the analogy milling process.

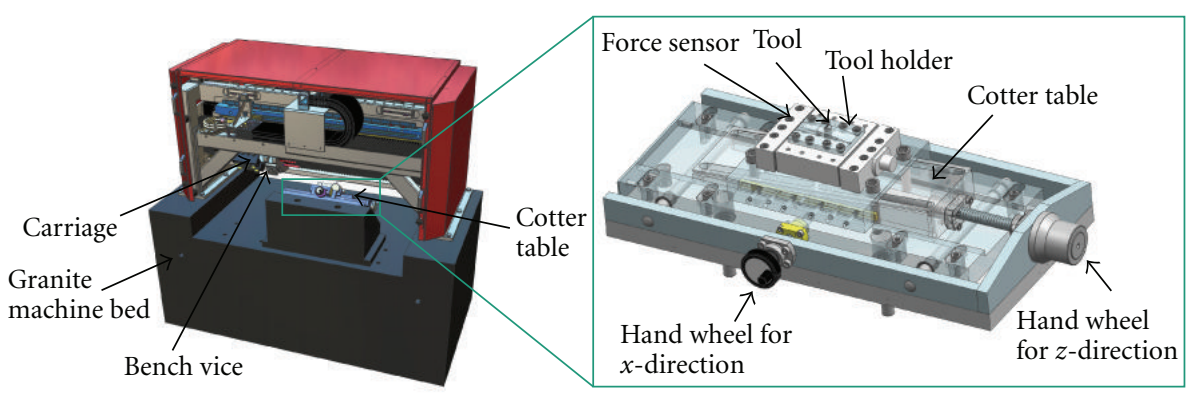

FIGURE 8: Setup of the novel analogy test bench for milling processes. 


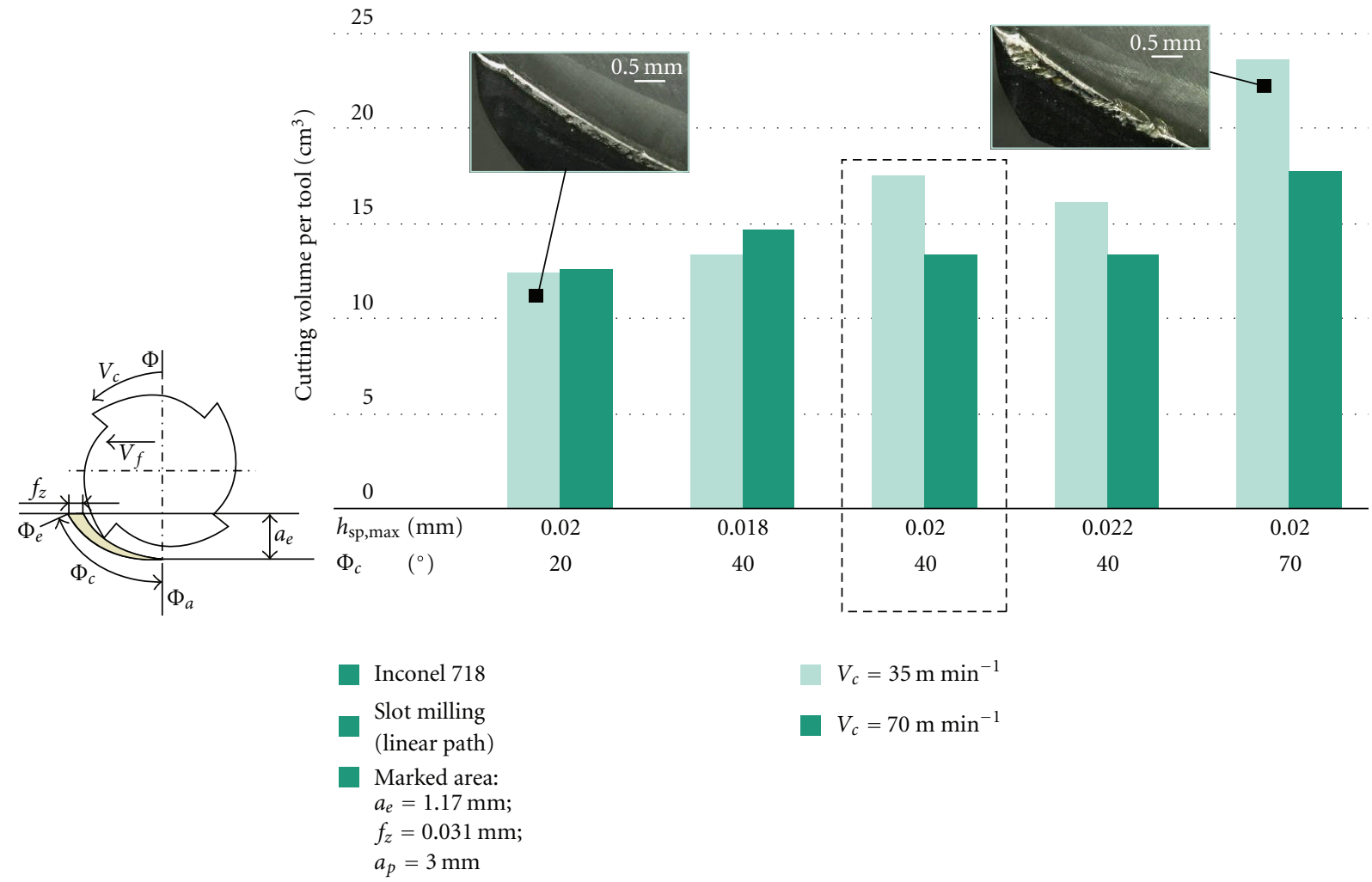

FIGURE 9: Influence of the tool engagement and the cutting velocity on the tools' cutting volume.

(a)
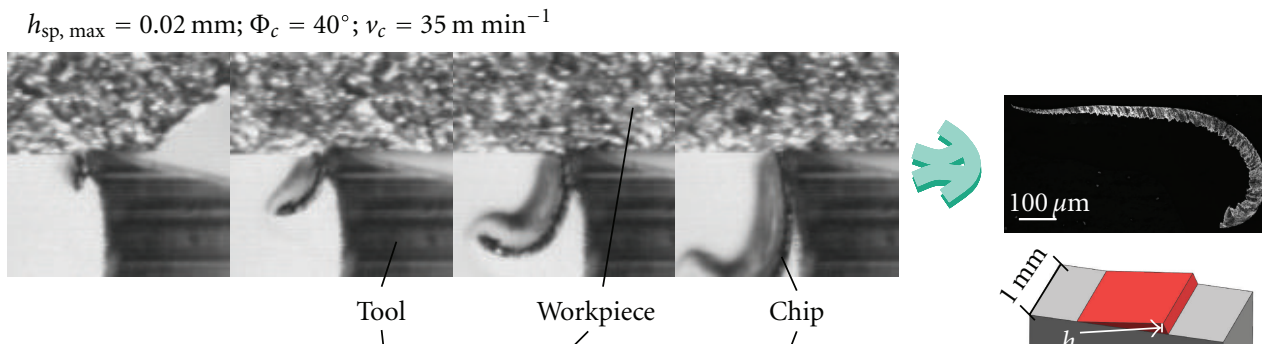

(b)
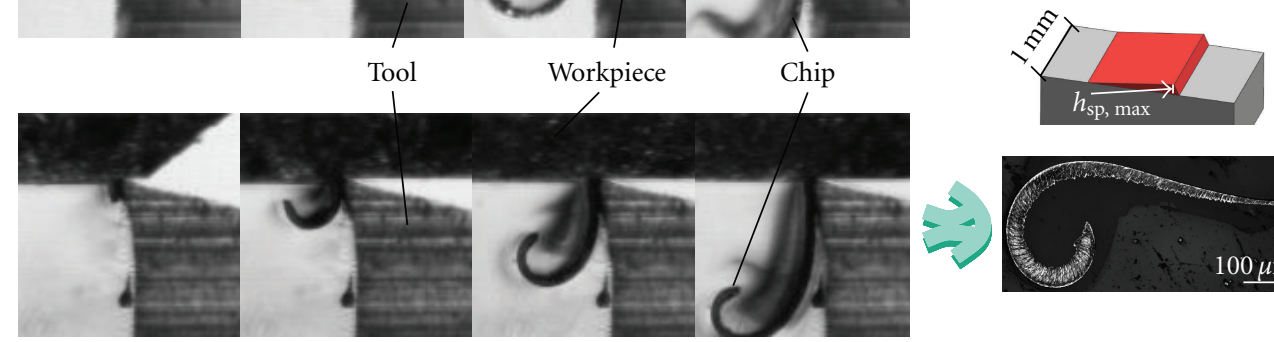

$h_{\mathrm{sp}, \max }=0.02 \mathrm{~mm} ; \Phi_{c}=40^{\circ} ; v_{c}=70 \mathrm{~m} \mathrm{~min}^{-1}$

FIgURE 10: Investigation of chip curve and serration; (a) low and (b) high chip curve and serration.

\section{Process Layout Optimization}

3.1. Description of Novel Test Bench. The novel test bench combines following two beneficial advantages that classifies it from other orthogonal cutting devices - a good accessibility and realization of a variable chipping geometry. The testbench-related methodology is based on a transformation of the uncut chip geometry from the rotatory real process to a translative analogy process; see Figure 7 . The evaluated uncut chip geometry can be displayed and manufactured in form of specimens.

To realize the translative movement of the analogy process, a hydrostatic mounted carriage conducts an onedimensional movement. The carriage guides the manufactured specimen, which is clamped in a high-precision bench vice, against the stationary tool where the chip formation process occurs; see Figure 8. The test bench includes measurement devices for forces as well as capacitive sensors. 
TABLE 1: Summary of cutting parameters.

\begin{tabular}{lc}
\hline Cutting velocity $\left(\mathrm{m} \mathrm{min}^{-1}\right)$ & $35-70$ \\
Max. uncut chip thickness $(\mathrm{mm})$ & $0,018-0,02-0,022$ \\
Engagement angle $\left({ }^{\circ}\right)$ & $20-40-70$ \\
Material & Inconel 718 \\
Process & Real analogy \\
\hline
\end{tabular}

The force measurement is provided by a three-component dynamometer Kistler9129AA and occurs tool sided. Furthermore, the good accessibility allows the implementation of a high-velocity camera as well as a thermography camera.

3.2. Experimental Setup. Based on real milling processes, which were conducted in form of slot cutting operations on the machine tool Heller MC25, analogy milling operations via the novel test bench were performed. To investigate the influence of the tool engagement angle on the cutting performance, this parameter was varied according to Table 1 . Moreover, the maximum uncut chip thickness $h_{\mathrm{sp} \text {, max }}$ was varied by keeping the engagement angle constant. The last parameter to be varied was the cutting velocity, between $35 \mathrm{~m} \mathrm{~min}^{-1}$ and $70 \mathrm{~m} \mathrm{~min}^{-1}$. All processes were performed in the nickel-based alloy Inconel 718 at forged state, indicating no significance in regard to the orientation of the grain structure. The applied carbide milling tools from Seco Jabro Tools were coated with a TiAlN layer and provided a diameter of $10 \mathrm{~mm}$, a cutting edge radius of $12 \mu \mathrm{m}$ and four teeth. To investigate and compare the real and analogy milling process sufficiently, multiple data was acquired, such as force and metallographic chip analysis as well as pictures using a highvelocity camera.

3.3. Results. To investigate the overall process performance of the applied milling tools within the shown parameter field, slot cutting operations were performed. The experimentations exhibit that the tool engagement angle $\Phi_{c}$ and the cutting velocity $v_{c}$ influence the achieved cutting volume significantly. Over the complete parameter set, a rapid wear progression could be found which, for higher cutting velocities and tool engagements, resulted in cutting edge chipping; see Figure 9. In this connection, it has to be pointed out that a land wear of $0,2 \mathrm{~mm}$ or cutting edge chipping constituted the abort criterion of the tests. Moreover, the chip serration significantly increased with the cutting velocity, whereas an enlargement of the engagement angle led to a degradation of the surface quality as well as to a burr formation at the machined workpieces resulting in a stronger abrasive tool wear. In order to relate these findings to proper actions for a systematic and efficient optimization of the milling process, fundamental and detailed knowledge regarding the chip formation process displays an indispensible must.

For this aim, analogy milling tests using the novel test bench were performed for the benefit of a fast, effective, and reproducible investigation of potential parameters for process optimization. The measured forces in the analogy tests conformed to the forces detected in the real milling tests. Thus, an assessment of the occurring forces during machining becomes possible by using the novel test bench. Similar to the slot milling tests, the analogy tests showed that the cutting force $F_{c}$ increased with the cutting velocity and the tool engagement, while the passive force $F_{p}$ decreased with the cutting velocity. This could be seen as an evidence for a decrease of deformation labour to be expended for the cutting process at elevated cutting velocities leading to a lower tool displacement and hence to consistent surface properties. This characteristic is confirmed by the analysis of the chip compression $\lambda_{\mathrm{sp}}$ which is defined as the relation of the covered cutting distance and the length of the chip. Here, a decrease of chip compression could be revealed for a raise of cutting velocity. Furthermore, the analysis of the chip serration, mainly depending on the grain structure of the machined workpiece material [8], showed a progression with the cutting velocity leading to higher fatigue stresses at the tools and hence to shorter tool life. In the frame of the analysis, it also was detected and visualized that higher chip curves lead to shorter contact length between the forming chip and the tool. This obviously results in higher surface pressures on the tools' rake face induced by the chip and hence to further wear progression. As it can be seen in Figure 10 for $h_{\mathrm{sp}, \max }=0,02 \mathrm{~mm}$ and $\Phi_{c}=40^{\circ}$, the chip curve varies with the cutting speed, (a) $v_{c}=35 \mathrm{~m} \mathrm{~min}^{-1}$ and (b) $v_{c}=70 \mathrm{~m} \mathrm{~min}^{-1}$, which can be visualized and analyzed via high-velocity camera and light microscope pictures.

The multiple data gained by using the novel analogy milling test bench illustrates the chip formation process in detail and therefore gives unprecedented hints for further optimizing the process parameter frame as well as the tool design for ambitious milling tasks.

\section{Conclusions}

In this paper, an integrated approach for a knowledge-based process layout for simultaneous 5-axis milling of advanced materials was introduced. Besides the optimization of the tool path itself, the high potential of optimizing the cutting parameters as well as the tool geometry was presented. Referring to this, an innovative test bench for a detailed analysis of the chip formation process was established.

\section{Acknowledgments}

The authors would like to thank the Fraunhofer Gesellschaft (FhG) for promoting this research within the project HybridHPC accomplished in the Fraunhofer Challenge Programme and the FhG-Innovation-Cluster "TurPro." G. F. Cabral is a Scholarship Holder of the Brazilian CAPES.

\section{References}

[1] R. Schafrik and R. Sprague, "Superalloy technology-a perspective on critical innovations for turbine engines," Key Engineering Materials, vol. 380, pp. 113-134, 2008.

[2] M. Balazinski, V. Songmene, and L. Kops, "Improvement of tool life through variable feed milling of inconel 600," CIRP Annals, vol. 44, no. 1, pp. 55-58, 1995. 
[3] K. Weinert, D. Biermann, and S. Bergmann, "Machining of high strength light weight alloys for engine applications," CIRP Annals, vol. 56, no. 1, pp. 105-108, 2007.

[4] N. Narutaki, Y. Yamane, K. Hayashi, T. Kitagawa, and K. Uehara, "High-speed Machining of Inconel 718 with Ceramic Tools," CIRP Annals, vol. 42, no. 1, pp. 103-106, 1993.

[5] M. Alauddin, M. A. El Baradie, and M. S. J. Hashmi, "Endmilling machinability of inconel 718," Journal of Engineering Manufacture, vol. 210, no. 1, pp. 11-23, 1996.

[6] E. O. Ezugwu, Z. M. Wang, and A. R. Machado, "The machinability of nickel-based alloys: a review," Journal of Materials Processing Technology, vol. 86, no. 1-3, pp. 1-16, 1998.

[7] G. Byrne, D. Dornfeld, and B. Denkena, "Advancing cutting technology," CIRP Annals-Manufacturing Technology, vol. 52, no. 2, pp. 483-507, 2003.

[8] L. Markworth, Fünfachsige schlichtfräsbearbeitung von strömungsflächen aus nickelbasislegierungen, Doctoral thesis, Aachen, Germany, 2005.

[9] G. Lebküchner, "Innovative frässtrategien für die bliskbearbeitung," in Proceedings of the Neue Technologien für die Luftund Raumfahrt, Hannover, Germany, 2004.

[10] M. Otkur and I. Lazoglu, "Trochoidal milling," International Journal of Machine Tools \& Manufacture, vol. 47, no. 9, pp. 1324-1332, 2007.

[11] F. Klocke, T. Bergs, M. Meinecke et al., "Model based optimization of trochoidal roughing of titanium," in Proceedings of the 12th CIRP Conference on Modeling of Machining Operations, Gaithersburg, Md, USA, 2008.

[12] S. Altmüller, Simultanes Fünfachsiges Fräsen von Freiformflächen aus Titan, Berichte aus der Produktionstechnik, 2001.

[13] F. Klocke and W. König, Fertigungsverfahren Drehen, Fräsen, Bohren, Springer, New York, NY, USA, 2008.

[14] N. Kardes and Y. Altintas, "Prediction of cutting forces in circular milling," in Proceedings of the 3rd International Conference and Exhibition on Design and Production of Dies and Molds, pp. 1-5, Bursa, Turkey, 2004.

[15] M. Meinecke, Prozessauslegung zum fünfachsigen zirkularen schruppfräsen von titanlegierungen, Doctoral thesis, Aachen, Germany, 2009.

[16] J. Köhler, Berechnung der zerspankräfte bei variierenden spanungsquerschnittsformen, Doctoral thesis, Hannover, Germany, 2010.

[17] K. C. Hui, "Solid sweeping in image space-application in NC simulation," The Visual Computer, vol. 10, no. 6, pp. 306-316, 1994.

[18] M. Stautner, Simulation und optimierung der mehrachsigen fräsbearbeitung, Doctoral thesis, Essen, Germany, 2005.

[19] E. Kose, A. Kurt, and U. Seker, "The effects of the feed rate on the cutting tool stresses in machining of Inconel 718," Journal of Materials Processing Technology, vol. 196, no. 1-3, pp. 165-173, 2008. 

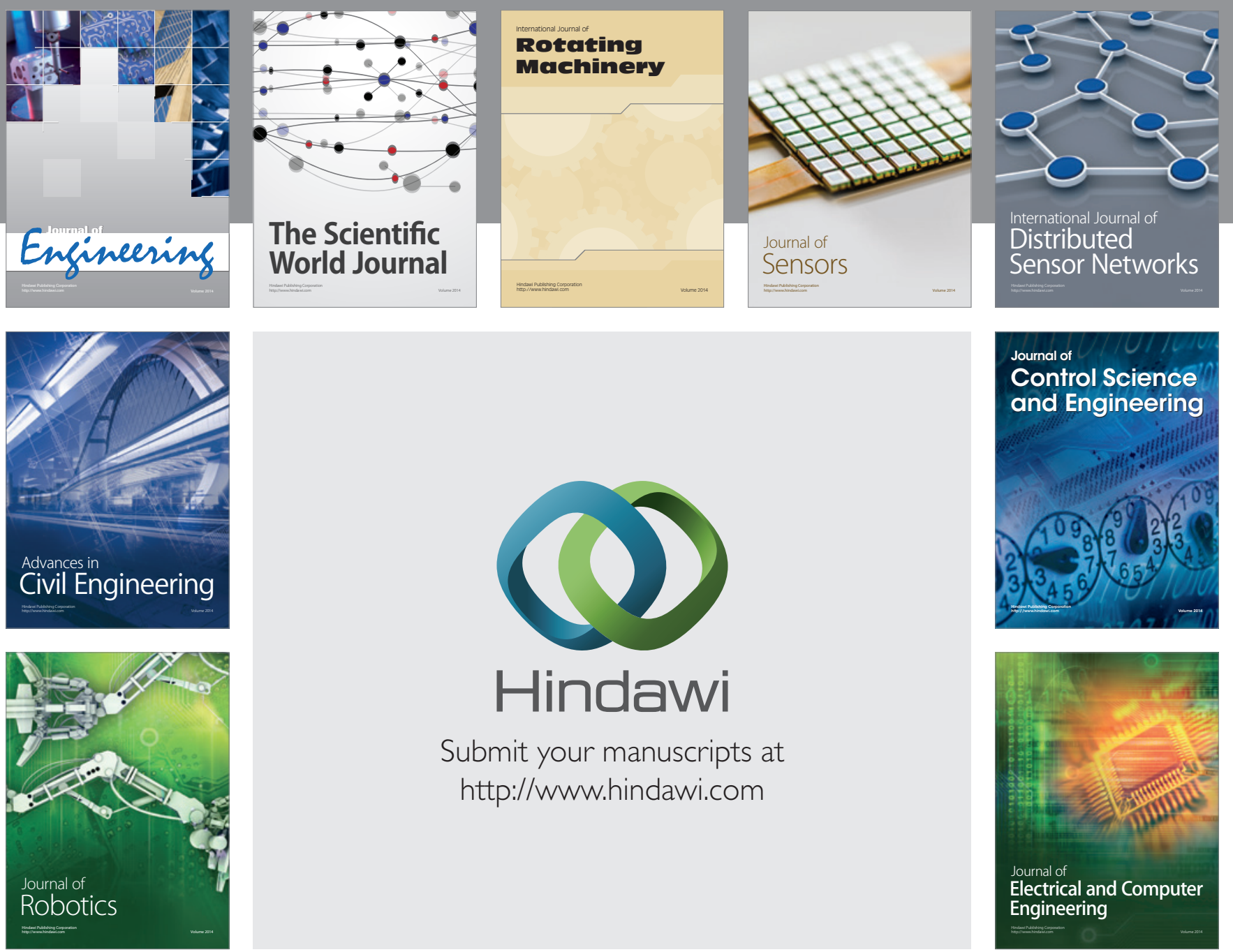

Submit your manuscripts at

http://www.hindawi.com
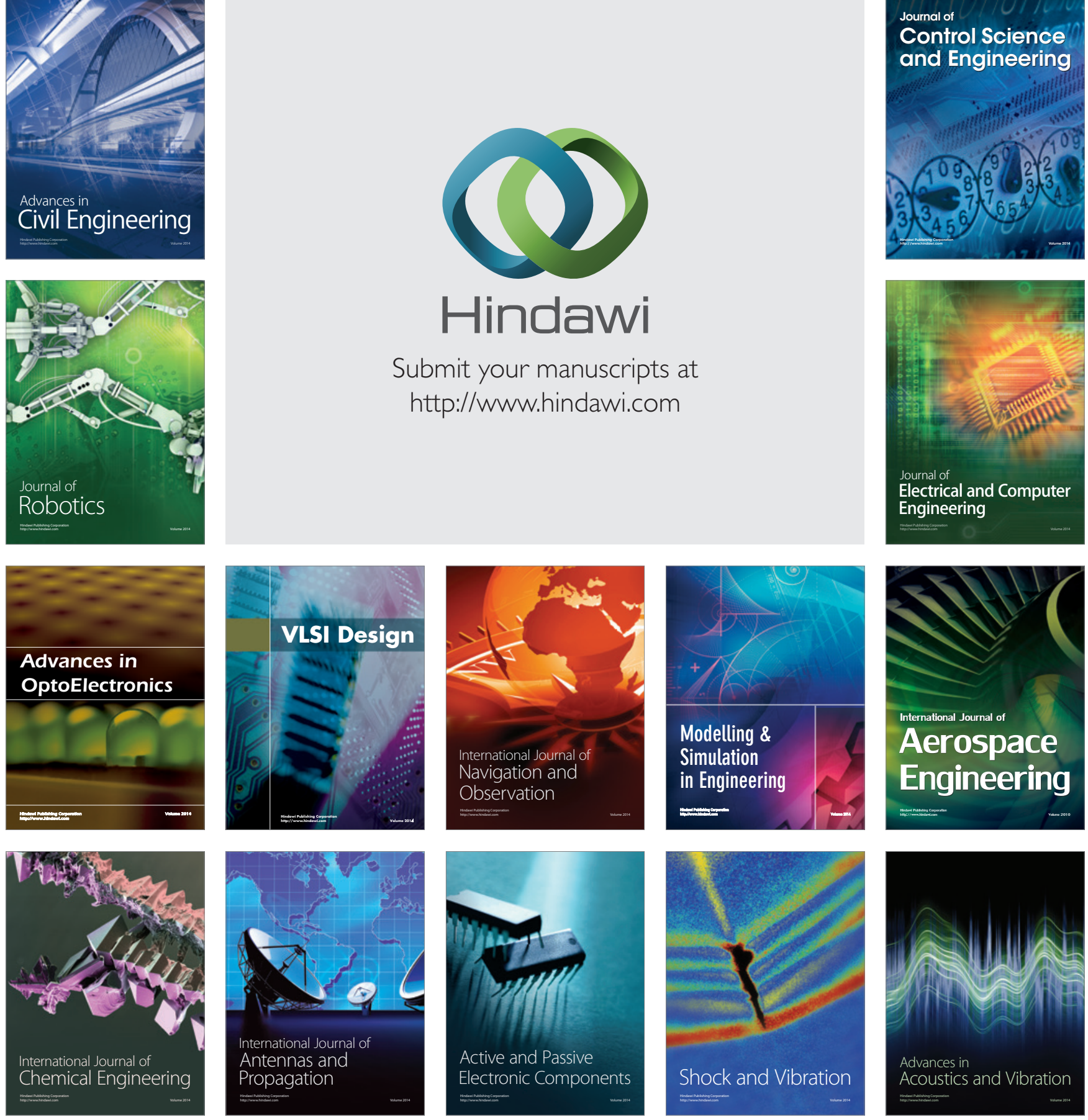